\title{
A Study on the Moderating Effect of Family Functioning on the Relationship between Deviant Peer Affiliation and Delinquency among Chinese Adolescents
}

\author{
Yunjiao Gao, Yanping Yu, Ting Kin Ng \\ Department of Applied Social Studies, City University of Hong Kong, Hong Kong, China \\ Email: yunjgao@cityu.edu.hk
}

Received April 23 $3^{\text {rd }}, 2013$; revised May $25^{\text {th }}, 2013$; accepted June $3^{\text {rd }}, 2013$

Copyright (C) 2013 Yunjiao Gao et al. This is an open access article distributed under the Creative Commons Attribution License, which permits unrestricted use, distribution, and reproduction in any medium, provided the original work is properly cited.

\begin{abstract}
This study examined the interaction effect between family functioning and delinquent peer association on delinquent behavior in a sample of 534 adolescents from five middle schools in Shenzhen, the People's Republic of China. The results showed that both exposure to delinquent peers and family functioning had significant main effects on delinquency, and family functioning significantly buffered the negative effect of association with deviant peers on delinquency. Further analyses using the five subscales of family functioning demonstrated that family harmony and parental concern were significantly predictive of delinquency, and harmony, parental concern and control significantly moderated the risk of affiliating with deviant peers. This study suggested that harmonious family environment with high levels of parental concern and parental control were effective in alleviating the negative impact of deviant peer association on delinquent behavior in the Chinese context.
\end{abstract}

Keywords: Family Functioning; Delinquent Peer Association; Delinquent Behavior; Chinese Adolescents

\section{Introduction}

Criminologists have long realized the roles that deviant peer affiliation and family play in the etiology of delinquency, and considerable literatures have investigated the relationship among these three variables. Several researchers have explored the moderating effect of family variables on the relationship between deviant peer association and delinquency, and have made mixed results (e.g., Coombs, Paulson, \& Richardson, 1991; Farrell, Henry, Mays, \& Schoeny, 2011; Galambos, Barker, \& Almeida, 2003; Keenan et al., 1995; Lansford et al., 2003; Mason, Cauce, Gonzales, \& Hiraga, 1994; Mrug \& Windle, 2009; Poole \& Regoli, 1979; Trucco, Colder, \& Wieczorek, 2011; Vitario, Brendgen, \& Tremblay, 2000; Warr, 1993; Zimmerman, Steinman, \& Rowe, 1998). It remains unclear whether the buffering effect of family functioning exists or not, as few studies have examined family at a systemic level.

Family and peer group are two important agents of socialization. Adolescents are most likely to spend more time with peers than family members. With this change, they are more susceptible to peer influence than their parents' suggestions and influences (Berndt, 1979). Exposure to deviant peers in adolescence has been documented to be one of the strongest correlates of juvenile delinquency (Elliott, Huisinga, \& Ageton, 1985; Loeber, Stouthamer-Loeber, Van Kammen, \& Farrington, 1991; Warr, 2002), and it has been found that peer pressure was more powerful than family environment in predicting delinquent behavior in early adolescence. Meanwhile, although the influence of family on adolescent development becomes powerless, parenting practices and family still exert significant protective effect by shielding adolescent children from engaging in delinquent behavior (e.g., Cantelon, 1994; Henry, Tolan, \& GormanSmith, 2001; Loeber, 1982; Yoshikawa, 1994). Therefore, while adolescents affiliating with deviant peers may be at increased risk of delinquency, well-functioning families may protect them from the negative influence of deviant peers, thus reducing the likelihood of involving in delinquency.

Existing studies on the relationship between family and juvenile delinquency have been predominately conducted in Western societies. It would be both practically and theoretically important to examine the relationship in the Chinese context. With the influence of Confucianism culture for a long time, Chinese people strongly emphasize the importance of family (Shek \& Lai, 2000) and Chinese families are unique to adopt filial piety for defining the relationship between the elder and the younger generation, which greatly affects family relationships (Ching, 1993). Chinese people might perceive family functioning in a different way from the westerners (Shek, 2001), and adolescents in China are generally more attached to and spend more time with their parents than peers (e.g., Chen, Dong, \& Zhou, 1997; Ekblad, 1986). However, with rapid modernization and social changes in this country, the social control of family has been weakened. Meanwhile, teenagers during adolescence put more emphasis on peer association, spend more time with peers, and are more easily influenced by their friends than any other life period (Brown, 1990; Larson \& Richards, 1991). To our knowledge, since few studies to date have explored how family and exposure to deviant peers contribute to 
delinquency in the Chinese context, the knowledge pertaining to this issue is still insufficient. This study will use a sample of Chinese adolescents to examine the interaction effect between family functioning and delinquent peer association on delinquency.

\section{Literature Review}

\section{Deviant Peer Affiliation and Delinquent Behavior}

According to differential association theory (Sutherland \& Cressey, 1978), delinquency is a learned behavior. Individuals communicate and interact with intimate persons to learn the techniques of committing crimes, as well as the motives, rationalizations, and attitudes favoring such behavior. Ample empirical evidence has demonstrated the core assumption of this theory, that association with deviant peers is a salient predictor of adolescents' involvement in delinquent behaviors (e.g., Akers \& Jensen, 2006; Elliot, Huizinga, \& Ageton, 1985; Henry, Tolan, \& Gorman-Smith, 2001; Herrenkohl et al., 2001; Johnson, 1979; Lipsey \& Derzon, 1998; O’Donnell, Hawkins, \& Abbott, 1995; Piquero, Gover, MacDonald, \& Piquero, 2005; Thornberry et al., 1994). Studies using Asian or Asian American samples also have documented the strong relationship between deviant peer affiliation and delinquency (e.g., Greenberger et al., 2000; Kim \& Goto, 2000; Le, Monfared, \& Stockdale, 2005; Lin \& Lin, 2007; Thai, 2003; Zhang \& Messner, 1996). For instance, drawing data from a sample of 246 male adolescents, the study by Henry and his associates (2001) demonstrated that youths interacting with violent peers were more prone to commit violent conducts. O'Donnell, Hawkins, and Abbott (1995) found that attachment to deviant friends resulted in higher rates of latter delinquency among a longitudinal sample of 412 teenage boys. Comparing data from 329 Chinese, Laotian, Cambodian, and Vietnamese youths, Le et al. (2005) showed that compared to school attachment, parent attachment and parental discipline, affiliating with deviant peers was the strongest predictor of delinquency, but the predictive power among the Chinese youths was the weakest.

\section{Family Functioning, Deviant Peer Association and Delinquent Behavior}

Social control theory assumes that individuals have an inclination to commit crime or delinquency, and social bond shields individuals from engaging in antisocial activities; if the social bond is weakened or broken, individuals are likely to commit self-interested behavior, like crime (Hirschi, 1969). Family is one of the conventional institutions to provide social control. As deviant peer association serves as an instigator of delinquency, family may be a barrier to the negative influence of deviant peers. In other words, family may play a role of moderator between deviant peer affiliation and delinquent behavior.

Compared to the large number of studies exploring the moderating effect of family variables on the relationship between deviant peer association and delinquency (e.g., Coombs, Paulson, \& Richardson, 1991; Farrell, Henry, Mays, \& Schoeny, 2011; Galambos, Barker, \& Almeida, 2003; Keenan et al., 1995; Lansford et al., 2003; Mason, Cauce, Gonzales, \& Hiraga, 1994; Mrug \& Windle, 2009; Poole \& Regoli, 1979; Trucco, Colder, \& Wieczorek, 2011; Vitario, Brendgen, \& Tremblay, 2000; Warr, 1993; Zimmerman, Steinman, \& Rowe, 1998), few have studied the moderating role of family functioning. Family func- tioning can be defined as "the quality of family life at the systemic level, such as wellness, competence, strengths, and weaknesses of a family" (Shek, 2005: p. 518). To the knowledge of the investigators, only one study conducted by Henry, Tolan, and Gorman-Smith (2001) adopted a composite score of family relationship (i.e., cohesion, communication, belief about family, shared deviant beliefs, support, and organization) and parenting practices (i.e., positive parenting, discipline effectiveness, discipline avoidance, monitoring/involvement) to investigate four possible models about the relationships among family functioning, peers and delinquency among 246 male adolescents. The four models included a moderated model, which hypothesized that family functioning could buffer the risk of deviant peers on delinquency. However, the empirical analyses failed to support this model. Despite adopting the concept of family functioning, this study did not use standardized family functioning scales, but a composite score of family relationship and parenting practices scales. Considering few studies have investigated the moderating effect of family functioning on the relationship between deviant peer affiliation and delinquency, it calls for further research to explore this issue.

The current study aims at filling the gaps by addressing three important issues. The first is to examine whether the relationship between deviant peer association and delinquency exists in the Chinese context. It can be hypothesized that affiliation with deviant peers is positively associated with delinquency. The second issue concerns the moderating effect of family functioning on the relationship between deviant peer association and delinquency. We postulate that family functioning buffers the negative influence of deviant peer association on juvenile delinquency. The third is to explore the interaction effect between each dimension of family functioning and deviant peer association on delinquent behavior. It can be expected that each dimension of family functioning attenuate the negative influence of deviant peer affiliation on delinquency.

\section{Method}

\section{Participants}

The data used in the study were obtained from a sample of 616 students in Grade 7 to 9 from five middle schools in Shenzhen, Guangdong Province. Shenzhen is the first and one of the most successful Special Economic Zones in China. The five middle schools were selected by convenience sampling. Two of the three public schools were located in the center areas of Shenzhen, in which most enrolled students are local students. Another public school was a reform school in the suburbs, to which the students were referred by parents, teachers, or police for minor delinquent conducts (Ren, 1996). The remaining two were private schools on the outskirts, with many migrant students without registering their household in Shenzhen.

There were 561 participants who returned valid questionnaires, and the response rate was $91.1 \%$. The cases with missing values in demographic variables were handled with listwise deletion. As a result, 27 cases were excluded from subsequent analyses, and the final data were composed of a total number of 534 adolescents ranging from the ages of 10 to $19(\mathrm{M}=13.84$, $\mathrm{SD}=1.24)$. More male adolescents $(61.8 \%)$ participated in the research than their female counterparts $(38.2 \%)$. The majority of the sample was non-singleton children $(70.2 \%)$, while the remainder $(29.8 \%)$ was only child. More than a half of the sample perceived their family economic level as average level 
(58.1\%), 26.2\% as above the average, $8.2 \%$ as below the average, $4.3 \%$ as wealthy and $3.2 \%$ as poor.

\section{Procedures}

Permission to conduct the study was granted by the University Research Ethics Committee and the principals of the selected middle schools. Consents were also obtained from the respondents' parents or other guardians. A parental/guardian consent form was sent to each student by the form teacher several days before delivering the questionnaire. Students took the consent form back to their home, asked their parents or other guardians to fill out the form and handed it to the form teacher when back to school. Only those with completed consent forms were finally recruited into the research.

Moreover, the questionnaire was administered by the researchers during the class time. At the beginning of each data collection session, the researcher emphasized the anonymity and confidentiality of the study, explained the research purpose, the rights of the participants as well as the instructions of filling out the questionnaire. The researcher provided assistance when the respondents had difficulty in responding to the questions. All questionnaires administration was completed during the first week of January 2012.

\section{Measures}

Family functioning. Family functioning was assessed by a revised version of the Chinese Family Assessment Instrument (C-FAI) (Shek, 2002). Since the Western scales of family functioning may not be applicable to non-Western contexts due to cultural differences (Morris, 1990), Shek (2002) developed an indigenous 33 -item scale to measure family functioning applicable to the Chinese context. Four items in the original C-FAI scale were deleted as they reduced the internal reliability of the scale, and finally 29 items were used in the study $(\alpha=.95)$. Participants were asked to indicate to what degree the situation described in the statement was similar to their family $(1=$ very dissimilar, 2 = somewhat dissimilar, $3=$ neither similar nor dissimilar, $4=$ somewhat similar, $5=$ very similar), which were opposite to the original scale. The scale consists of 5 subscales, which are 1$)$ mutuality ( $\alpha=.92$; e.g., "Family members support each other", "Family members love each other", "Family members care each other"); 2) communication ( $\alpha=.90$; e.g., "Family members talk to each other", "Family members enjoy getting together", "Not much barrier among family members"); 3 ) conflict and harmony ( $\alpha=.69$; e.g., "No mutual concern", "Much friction among family members", "Frequent fighting among family members"); 4) parental concern ( $\alpha=.72$; e.g., "Parents love their children", "Parents do not concern their children", "Parents take care of their children"); and 5) parental control $(\alpha=.78$; e.g., "Parents scold and beat children", "Parents force children to do things", "Parents' control is too harsh"). Higher scores indicate higher levels of family functioning.

Deviant peer affiliation. Deviant peer association was measured by 18 items. Respondents were asked to indicate how many of their close friends had such behavior and experiences during the past six months, like playing truancy, running away from home, going to internet café, cheating on exams, watching pornography, drinking alcohol, smoking, carrying weapons, fighting, bullying, extortion, stealing, gambling, and damaging property. The last two items referred to whether or not their friends were punished by teachers, school authority, or police. Participants rated each item on a 3 -point scale $(1=$ none of them, $2=$ a few of them, $3=$ most of them). The scale had high internal reliability $(\alpha=.94)$. A higher total score refers to a higher level of deviant peer association.

Delinquency. The 27-item delinquency scale was adapted from the measures by Arnold (1965) as well as Elliott and Ageton (1980), which were combined with the delinquent behaviors prescribed by Preventing Juvenile Delinquency Law (1999) and Juvenile Protection Law of People's Republic of China (2006). The scale $(\alpha=.92)$ contained four categories of delinquency: underage acts, substance use, violent delinquency, and property delinquency. The underage acts included playing truancy, running away from home, loitering during midnight, going to internet café, buying alcohol or cigarettes, cheating on exams, reading pornographic materials, and driving a car without license. Substance use encompassed drinking alcohol, getting drunk, smoking cigarettes, and taking illegal drugs. Violent delinquency consisted of carrying weapons, fighting, insulting other people, bullying other students, extortion, insulting parents, and hitting parents. Property delinquency contained taking money from home without parents' permission, stealing, shoplifting, painting graffiti, damaging property, and gambling. Participants rated how often they engaged in these delinquent behaviors in the past six months $(1=$ never, $2=$ seldom, $3=$ sometimes, $4=$ frequently, $5=$ always). A higher summated score indicates a higher level of delinquency.

Demographic variables. Demographic variables contained adolescents' gender (male or female), age, perceived economic status, and singleton status (single child or non-single child). As for the appraisal of perceived economic status, adolescents rated on a 5 -point scale on the family economic condition $(1=$ poor, $2=$ below the average, $3=$ on the average, $4=$ above the average, $5=$ wealthy).

\section{Results}

\section{Descriptive Statistics}

The means, standard deviations, and intercorrelations for the measures of delinquent peer association, family functioning and delinquency are presented in Table $\mathbf{1}$. With regard to the intercorrelational relationships, deviant peer affiliation was substantially related to delinquency $(\mathrm{r}=.49, p<.001)$. While the family functioning total score had a moderate negative association with delinquency $(\mathrm{r}=-.33, p<.001)$, the correlations between the five family functioning subscales and delinquency were significant but lower $(\mathrm{rs}=-.22$ to $-.31, \mathrm{ps}<.001)$ than the total score. Besides, delinquent peer association was negatively correlated with total family functioning $(\mathrm{r}=-.18, p<.001)$ and the five subscales ( $\mathrm{rs}=-.10$ to $-.17, p \mathrm{~s}<.05)$.

\section{Main Effects of Peer Delinquency and Family Functioning}

A hierarchical regression analysis was conducted to examine the main effects of deviant peer affiliation and total family functioning and their interaction effect on delinquency. As recommended by Aiken and West (1991), deviant peer affiliation and total family functioning were mean-centered, and an interaction term was computed by multiplying the mean-centered predictors. For the control variables, age and perceived 
Table 1.

Means, standard deviations, and zero-order correlations for major variables $(\mathrm{N}=534)$.

\begin{tabular}{|c|c|c|c|c|c|c|c|c|}
\hline & 1 & 2 & 3 & 4 & 5 & 6 & 7 & 8 \\
\hline Total Family Functioning & - & & & & & & & \\
\hline Mutuality & $.93^{* * *}$ & - & & & & & & \\
\hline Harmony & $.74^{* * *}$ & $.64^{* * *}$ & - & & & & & \\
\hline Communication & $.91^{* * *}$ & $.82^{* * *}$ & $.50^{* * *}$ & - & & & & \\
\hline Parental Concern & $.73^{* * *}$ & $.63^{* * *}$ & $.51^{* * *}$ & $.58^{* * *}$ & - & & & \\
\hline Parental Control & $.61^{* * *}$ & $.43^{* * *}$ & $.51^{* * *}$ & $.41^{* * *}$ & $.45^{* * *}$ & - & & \\
\hline Deviant Peer Association & $-.18^{* * *}$ & $-.17^{* * *}$ & $-.10^{*}$ & $-.16^{* * *}$ & $-.14^{* *}$ & $-.16^{* * *}$ & - & \\
\hline Delinquency & $-.33^{* * *}$ & $-.28^{* * *}$ & $-.26^{* * *}$ & $-.27^{* * *}$ & $-.31^{* * *}$ & $-.22^{* * *}$ & $.49^{* * *}$ & - \\
\hline M & 110.05 & 35.26 & 19.70 & 31.97 & 12.38 & 10.75 & 24.10 & 33.27 \\
\hline SD & 22.82 & 8.02 & 4.20 & 9.00 & 2.85 & 3.28 & 6.95 & 10.05 \\
\hline
\end{tabular}

Note: ${ }^{*} p<.05 ;{ }^{* *} p<.01 ;{ }^{* * *} p<.001$.

family economic status were mean-centered, and gender $(1=$ male, $-1.62=$ female $)$ and singleton status $(1=$ single child, $-.42=$ non-single child) were weighted-effect coded. Using the centered predictors, the first-order regression coefficients represented the average main effects of the corresponding predictors across the range of the other predictors (Aiken \& West, 1991). The control variables were included in block 1. Delinquent peer association and family functioning were entered into block 2 to investigate their main effects. In block 3, the interaction term was added.

Table 2 shows the summary of the hierarchical regression analysis. The control variables were significantly predictive of delinquency, $\mathrm{R}^{2}=.11, \mathrm{~F}(4,529)=16.03, p<.001$. Two of the four control variables, age $(\mathrm{B}=1.50, \mathrm{t}=4.42, p<.001)$ and gender $(\mathrm{B}=1.77, \mathrm{t}=5.33, p<.001)$, were positively related to adolescents' delinquency, suggesting that males and older teenagers were more prone to conduct delinquent behavior, whereas singleton status and family economic status were not significantly linked to delinquency. After controlling for the demographic variables, deviant peer affiliation and total family functioning significantly affected delinquency, $\Delta \mathrm{R}^{2}=.25, \Delta \mathrm{F}(2$, $527)=100.54, p<.001$. Deviant peer affiliation had a strong positive main effect on delinquency $(\mathrm{B}=.59, \mathrm{t}=6.61, p<.001)$, whereas total family functioning was negatively related to delinquency $(\mathrm{B}=-.10, \mathrm{t}=-11.20, p<.001)$. The results revealed that peer delinquency was a risk factor for delinquency, while good family functioning played a protective role to shield them from engaging in delinquent conduct.

\section{Interaction Effect between Peer Delinquency and Family Functioning}

There was a significant interaction between delinquent peer association and total family functioning $\left(\Delta \mathrm{R}^{2}=.02, \mathrm{~B}=-.01, \mathrm{t}\right.$ $=-3.77, p<.001$ ), which evidenced the existence of the moderating effect of total family functioning on the relationship between deviant peer affiliation and delinquency. Following the recommendations by Aiken and West (1991), a further analysis of the conditional effects of delinquent peer association on delinquency at low (one standard deviation below the mean) and high (one standard deviation above the mean) values of
Table 2.

Hierarchical multiple regression for predicting delinquency $(\mathrm{N}=543)$.

\begin{tabular}{cccc}
\hline Variable & Block 1 & Block 2 & Block 3 \\
\hline Gender & $1.77^{* * *}$ & $1.50^{* * *}$ & $1.49^{* * *}$ \\
Singleton Status & 1.04 & .36 & .38 \\
Age & $1.50^{* * *}$ & $.92^{* *}$ & $1.00^{* * *}$ \\
Family Economic Status & -.14 & .05 & -.03 \\
$\begin{array}{c}\text { Deviant Peer Association } \\
\text { (DPA) }\end{array}$ & & $.59^{* * *}$ & $.57^{* * *}$ \\
$\begin{array}{c}\text { Total Family Functioning } \\
\text { (FF) }\end{array}$ & & $-.10^{* * *}$ & $-.10^{* * *}$ \\
DPA $\times$ FF & & & $-.01^{* * *}$ \\
$\mathrm{R}^{2}$ & .11 & .35 & .37 \\
$\mathrm{~F}$ & $16.03^{* * *}$ & $48.22^{* * *}$ & $44.41^{* * *}$ \\
$\Delta \mathrm{R}^{2}$ & & .25 & .02 \\
$\Delta \mathrm{F}$ & & $100.54^{* * *}$ & $14.25^{* * *}$ \\
\hline
\end{tabular}

Note: Unstandardized coefficients are presented. Gender and singleton status are weight-effect coded. Age, family economic status, total family functioning, and deviant peer association are mean-centered.

total family functioning was conducted. The simple slopes are illustrated in Figure 1. The impact of deviant peer association on delinquency was weaker when total family functioning was high $(\mathrm{B}=.46, \mathrm{t}=6.05, p<.001)$ than when that was low (B $=.79, \mathrm{t}=11.49, p<.001)$, suggesting that healthy family functioning significantly decreased the influence of deviant peer association.

\section{The Main Effects of and Interaction Effects between Each Dimension of Family Functioning and Deviant Peer Affiliation on Delinquency}

Another hierarchical regression analysis was performed to test the main effects and the moderating effects of the family functioning subscales. Similarly, control variables were entered 


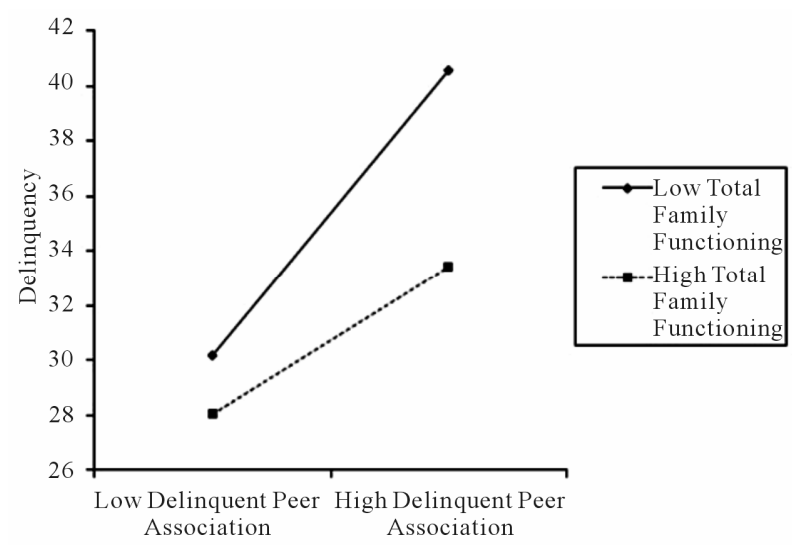

Figure 1.

Conditional effects of deviant peer association on delinquency at different levels of total family functioning.

in the first step. The mean-centered family functioning subscales and deviant peer association were entered in the second step. In the final step, five interaction terms which were formed by multiplying the mean-centered family functioning subscales and deviant peer association were entered.

Table 3 shows the summary of the hierarchical regression analysis. After controlling for demographic variables, the influences of family functioning subscales and delinquent peer association were significant, $\Delta \mathrm{R}^{2}=.26, \Delta \mathrm{F}(6,523)=35.09, p$ $<.001$. Deviant peer association was still strongly predictive of delinquency $(\mathrm{B}=.59, \mathrm{t}=11.31, p<.001)$. Harmony $(\mathrm{B}=-.26$, $\mathrm{t}=-2.21, p=.027)$ and parental concern $(\mathrm{B}=-.49, \mathrm{t}=-2.91$, $p=.004$ ) had significantly negative relation to delinquency, while the other three subscales, mutuality, communication, and parental control, were not significantly associated with delinquency. The results suggested that adolescents with more delinquent friends were more likely to involve in delinquency, and a family with better functioning in terms of harmony and parental concern made young people engaged in less delinquent behavior.

Furthermore, the combination of the interaction effects between the five family function subscales and deviant peer association was significant, $\Delta \mathrm{R}^{2}=.06, \Delta \mathrm{F}(5,518)=9.86, p<.001$. The delinquent peer association $\times$ harmony interaction was significant $(\mathrm{B}=-.04, \mathrm{t}=-2.43, p=.015)$. Figure 2 illustrates the conditional effects of deviant peer association on delinquency at different levels (one standard deviation above and below the mean) of harmony. The impact of deviant peer association on delinquency was weaker when harmony was high (B $=.37, \mathrm{t}=4.32, p<.001)$ than when that was low $(\mathrm{B}=.71, \mathrm{t}=$ $8.00, p<.001)$. As shown in Figure 3, there was also a significant deviant peer association $\times$ parental concern interaction $(B$ $=-.12, \mathrm{t}=-5.44, p<.001)$. The relationship between delinquent peer association and delinquency increased as parental concern decreased from low $(\mathrm{B}=.20, \mathrm{t}=2.27, p=.023)$ to high $(\mathrm{B}=.87, \mathrm{t}=11.88, p<.001)$. These results revealed that better family functioning in the forms of higher levels of harmony and paternal concern buffered the negative impact of deviant peer association on delinquency.

Besides, the deviant peer association $\times$ parental control interaction was significant in an unexpected direction $(\mathrm{B}=.06, \mathrm{t}$ $=3.11, p=.002$ ). As demonstrated in Figure 4, the contribution of deviant peer association on delinquency was stronger
Table 3.

Hierarchical multiple regression for predicting delinquency $(\mathrm{N}=543)$.

\begin{tabular}{|c|c|c|c|}
\hline Variable & Block 1 & Block 2 & Block 3 \\
\hline Gender & $1.77^{* * *}$ & $1.38^{* * *}$ & $1.38^{* * *}$ \\
\hline Singleton Status & 1.04 & .48 & .40 \\
\hline Age & $1.50^{* * *}$ & $.93^{* *}$ & $.98^{* * *}$ \\
\hline Family Economic Status & -.14 & .08 & .08 \\
\hline Deviant Peer Association (DPA) & & $.59^{* * *}$ & $.54^{* * *}$ \\
\hline Mutuality & & .03 & .01 \\
\hline Harmony & & $-.26^{*}$ & $-.26^{*}$ \\
\hline Communication & & -.10 & -.09 \\
\hline Parental Concern & & $-.49^{* *}$ & $-.44^{* *}$ \\
\hline Parental Control & & .00 & .01 \\
\hline DPA $\times$ Mutuality & & & .01 \\
\hline DPA $\times$ Harmony & & & $-.04^{*}$ \\
\hline DPA $\times$ Communication & & & .01 \\
\hline DPA $\times$ Parental Concern & & & $-.12^{* * *}$ \\
\hline DPA $\times$ Parental Control & & & $.06^{* *}$ \\
\hline $\mathrm{R}^{2}$ & .11 & .36 & .42 \\
\hline $\mathrm{F}$ & $16.03^{* * *}$ & $29.94^{* * *}$ & $24.94^{* * *}$ \\
\hline$\Delta \mathrm{R}^{2}$ & & .26 & .06 \\
\hline$\Delta \mathrm{F}$ & & $35.09^{* * *}$ & $9.86^{* * *}$ \\
\hline
\end{tabular}

Note: Unstandardized coefficients are presented. Gender and singleton status are weight-effect coded. Age, family economic status, deviant peer association, and the five family functioning subscales are mean-centered.

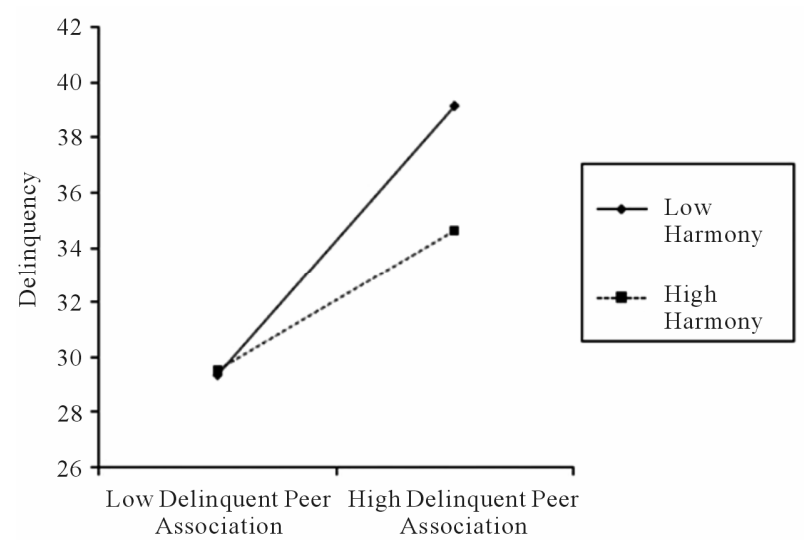

Figure 2.

Conditional effects of deviant peer association on delinquency at different levels of harmony.

with high $(\mathrm{B}=.73, \mathrm{t}=8.71, p<.001)$ than with low parental control scores $(\mathrm{B}=.34, \mathrm{t}=4.26, p<.001)$. Therefore, better family functioning in terms of more flexible parental control increased rather than buffered the effect of delinquent peer association on delinquency. 


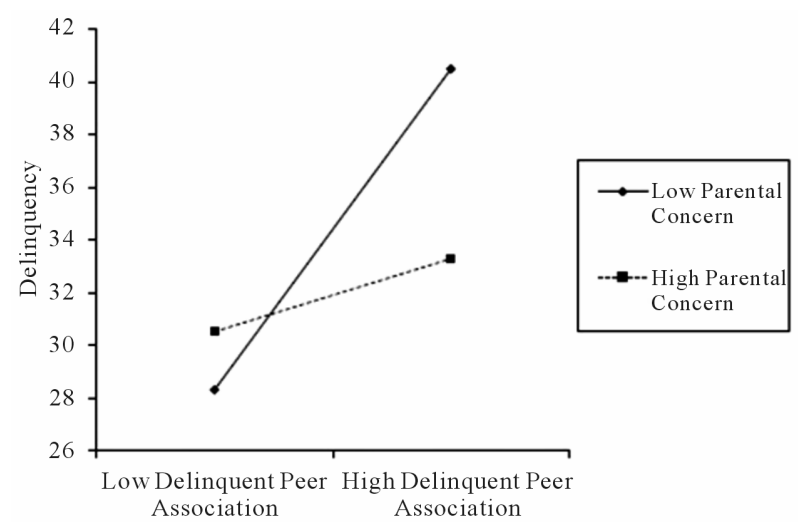

Figure 3.

Conditional effects of deviant peer association on delinquency at different levels of parental concern.

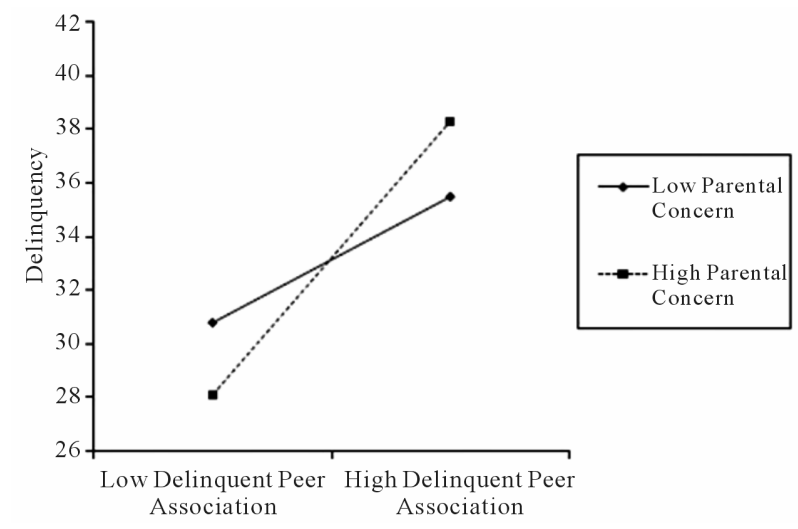

Figure 4.

Conditional effects of deviant peer association on delinquency at different levels of parental control. A lower parental control subscale score means harsher parental control and a higher score refers to more flexible parent control.

\section{Discussion}

The current study aimed at investigating the moderating effect of family functioning on the relation of deviant peer association to delinquency in the Chinese context. The results demonstrated that exposure to deviant peers was strongly predictive of juvenile delinquency, which were consistent with the vast majority of literature (e.g., Akers \& Jensen, 2006; Herrenkohl et al., 2001; Piquero, Gover, MacDonald, \& Piquero, 2005). The findings suggested that affiliating with deviant peers was a salient risk factor for delinquency among Chinese adolescents. Additionally, previous studies have evidenced the direct negative linkage between family functioning and juvenile delinquency (e.g., Barrera, Biglan, Ary, \& Li, 2001; Shek, 2005; Cashwell \& Vacc, 1996; Schwartz et al., 2005; Sullivan, 2006), and families of delinquents are more dysfunctional than their counterparts (Avci \& Gucray, 2010; Kim \& Kim, 2008). In line with those findings, the present study indicated that family functioning had a negative main effect on delinquency. Moreover, few studies have explored the interaction effect between delinquent peer association and family functioning on delinquency. The study documented the moderating role of family functioning. It not only directly reduced the level of delinquency, but also moderated the negative influence of delinquent peers. Healthy family functioning is more effectual to protect adolescents associating with deviant peers from conducting delinquency, whereas adolescents in dysfunctioning families are more prone to be influenced by deviant peers and to involve in delinquency.

With respect to the effects of the particular dimensions of family functioning, family harmony and parental concern were negatively related to delinquency. Numerous studies have demonstrated that families with less cohesion are related to high levels of delinquency (e.g., Gorman-Smith et al., 1996; Henry, Tolan, \& Gorman-Smith, 2001), and parental rejection is significantly predictive of delinquency (e.g., Loeber \& Stouthamer-Loeber, 1986; Buschgens et al., 2010; Duncan, 1971). To some degree, the results in the Chinese context are consistent with the Western findings.

Furthermore, the current study demonstrated that three domains of family functioning, family harmony, parental concern, and parental control, had buffering effects on the relation of deviant peer association to delinquency. The results suggested that harmonious family environment and parental concern played a crucial role in alleviating the risk of peer delinquency. Besides, the direction of the interaction between deviant peer association and parental control was opposite to those between parental concern and family harmony and exposure to deviant peers. The result revealed that flexible parental control increased the effect of deviant peer association on delinquency, and conversely, harsh control buffers the negative influence of peer delinquency. Figure 4 also indicated that excessively flexible parental control strengthened the relationship between deviant peer affiliation and delinquency, and respondents with high levels of harsh control conducted more delinquency at a low level of peer delinquency. Therefore, it is plausible to infer that adolescents with more intensive parental control and associating with fewer delinquent peers are more likely to conduct delinquency, while the ones receiving more flexible parental control and affiliating with more delinquent friends are also prone to have more delinquent behavior perhaps due to peer influence and insufficient parental control.

It is consistent with the findings by Galambos, Barker, and Almeida (2003), that firm parental behavioral control prevented the increasing trend of externalizing behaviors among adolescents affiliating with deviant friends. The findings supported the protective role parental control played in diminishing the risk of peer delinquency, and suggested that when adolescents associated with delinquent peers, harsh parental control is more effective in moderating the negative effect of peer delinquency on delinquent behavior. Parents should use more harsh control to discipline their children, thereby alleviating the risk of associating with deviant peers.

The study has some implications for prevention. Since deviant peer association has been consistently a strong predictor of delinquency in the Western and Chinese context, deviant peers should be the dominant target of prevention. Besides, as healthy family functioning had negative main effect on delinquency and mitigated the negative influence of peer delinquency in the study, interventions also should focus on family domains and improve the level of healthy family functioning. In particular, the programs that aim at improving harmonious family atmosphere and teaching parenting skills may be most effective in preventing juvenile delinquency.

It is noteworthy that the current study has some limitations. First, since the unbalanced economic and social development 
widely exists among different regions of China, and the research site, Shenzhen, represents the most developed areas, it must be cautious when generalizing the research findings to the developing regions. Second, considering the cross-sectional nature of this study, the causality between deviant peer association, family functioning and delinquency cannot be drawn, and should be further examined by longitudinal studies. Third, as for the measurement of deviant peer association, the current study adopted the conventional perceptual method to measure delinquent peer affiliation, which may result in the misperceptions of peer delinquency, as respondents have an inclination to project their behaviors on their friends (e. g., Elliott \& Menard, 1996; Kandel, 1996; Loeber et al., 1998). An alternative method, the social network method, makes respondents identify their friends and directly obtain data from those individuals. The latter method is more valid and accurate to reflect the level of deviant peers association.

Despite the limitations, the current research contributed to the existing literatures by documenting the moderating effects of family functioning and its specific dimensions on the relationship between deviant peer affiliation and delinquency in the Chinese context. Further studies should adopt longitudinal methodology and select data from various regions, developing and developed, urban and rural areas in China to confirm these findings. Other contextual factors, like teacher support, school environment, friendship distance distinguished by social network methods, can be combined with family variables to examine their effects on the relationship between deviant peer association and delinquency. Studies exploring the mechanism of how these variables operate in the development of delinquency are also valuable.

\section{REFERENCES}

Aiken, L. S., \& West, S. G. (1991). Multiple regression: Testing and interpreting interactions. Newbury Park: Sage.

Akers, R. L., \& Jensen, G. F. (2006). The empirical status of social learning theory of crime and deviance: The past, present, and future. In F. T. Cullen, J. P. Wright, \& K. R. Blevins (Eds.), Taking Stock: The Status of Criminological Theory (Vol. 15, pp. 37-76). New Brunswick, NJ: Transactions Publishers.

Arnold, W. R. (1965). Continuities in research: Scaling delinquent behavior. Social Problems, 13, 59-66. doi:10.2307/799306

Avci, R., \& Gucray, S. S. (2010). An investigation of violent and nonviolent adolescents' family functioning, problems concerning family members, anger and anger expression. Educational Science: Theory \& Practice, 10, 65-77.

Barrera, M., Biglan, A., Ary, D., \& Li, F. Z. (2001). Replication of a problem behavior model with American Indian, Hispanic, and Caucasian youth. Journal of Early Adolescence, 21, 133-157. doi:10.1177/0272431601021002001

Beijing Morning Post (2007). The rates of juvenile delinquency is increasing and the total number will rise in the coming five years. http://news.xinhuanet.com/legal/2007-01/11/content_5592096.htm

Berndt, T. J. (1979). Developmental changes inconformity to peers and parents. Developmental Psychology, 15, 606-616. doi:10.1037/0012-1649.15.6.608

Brown, B. B. (1990). Peer groups and peer cultures. In S. S. Feldman, \& G. R. Elliott (Eds.), At the threshold: The developing adolescent (pp. 171-196). Cambridge, MA: Harvard University Press.

Buschgens, C. J. M., van Aken, M. A., Swinkels, S. H. N., Ormel, J., Verhulst, F. C., \& Buitelaar, J. K. (2010). Externalizing behaviors in preadolescents: Familial risk to externalizing behaviors and perceived parenting styles. European Child \& Adolescent Psychiatry, 19, 567-575. doi:10.1007/s00787-009-0086-8

Cantelon, S. L. (1994). Family strengthening for high-risk youth. Wa- shington DC: Office of Juvenile Justice and Delinquency Prevention. Cashwell, C. S., \& Vacc, N. A. (1996). Family functioning and risk behaviors: Influences on adolescent delinquency. The School Counselor, 44, 105-114.

Chen, Y., Dong, Q., \& Zhou, H. (1997). Authoritative and authoritarian parenting practices and social and school performance in Chinese children. International Journal of Behavioral Development, 21, 855873. doi: $10.1080 / 016502597384703$

Coombs, R. H., Paulson, M. J., \& Richardson, M. A. (1991). Peer V. S. parental influence in substance use among Hispanic and Anglo children and adolescents. Journal of Youth and Adolescence, 20, 73-88. doi:10.1007/BF01537352

Duncan, P. (1971). Parental attitudes and interactions in delinquency. Child Development, 42, 1751-1765. doi:10.2307/1127582

Ekblad, S. (1986). Relationships between child-rearing practice and primary school children's functional adjustment in the People's Republic of China. Scandinavian Journal of Psychology, 27, 220-230. doi:10.1111/j.1467-9450.1986.tb01199.x

Elliott, D. S., \& Ageton, S. S. (1980). Reconciling race and class differences in self-reported and official estimates of delinquency. American Sociological Review, 45, 95-110. doi:10.2307/2095245

Elliott, D. S., \& Menard, S. (1996). Delinquent friends and delinquent behavior: Temporal and developmental patterns. In J. D. Hawkins (Ed.), Delinquency and crime: Current theories (pp. 28-67). Cambridge: Cambridge University Press.

Elliott, D. S., Huizinga, D., \& Ageton, S. S. (1985). Explaining delinquency and drug use. Beverly Hills: Sage Publications.

Galambos, N. L., Barker, E. T., \& Almeida, D. M. (2003). Parents do matter: Trajectories of change in externalizing and internalizing problems in early adolescence. Child Development, 74, 578-594. doi:10.1111/1467-8624.7402017

Gorman-Smith, D., Tolan, P. H., Zelli, A., \& Huesmann, L. R. (1996). The relation of family functioning to violence among inner-city minority youths. Journal of Family Psychology, 10, 115-129. doi:10.1037/0893-3200.10.2.115

Greenberger, E., Chen, C., Beam, M., Whang, S. M., \& Dong, Q. (2000). The perceived social contexts of adolescents' misconduct: A comparative study of youths in three cultures. Journal of Research on Adolescence, 10, 369-392. doi:10.1207/SJRA1003 7

Henry, D. B., Tolan, P. H., \& Gorman-Smith, D. (2001). Longitudinal family and peer group effects on violence and nonviolent delinquency. Journal of Clinical Child Psychology, 30, 172-186. doi:10.1207/S15374424JCCP3002 5

Herrenkohl, T. I., Huang, B., Kosterman, R., Hawkins, J. D., Catalano, R. F., \& Smith, B. H. (2001). A comparison of social development processes leading to violent behavior in late adolescence for childhood initiators and adolescent initiators of violence. Journal of Research in Crime and Delinquency, 38, 45-63. doi: $10.1177 / 0022427801038001003$

Hirschi, T. (1969). Causes of delinquency. Berkeley: University of California Press.

Johnson, R. E. (1979). Juvenile delinquency and its origins. Cambridge: Cambridge University Press.

Juvenile Protection Law of the People's Republic of China (2006). fromhttp://www.gov.cn/flfg/2006-12/29/content_554397.htm

Kandel, D. B. (1996). The parental and peer contexts of adolescent deviance: An algebra of interpersonal influences. Journal of Drug Issue, 26, 289-315.

Keenan, K., Loeber, R., Zhang, Q., Stouthamer-Loeber, M., \& Van Kammen, W. B. (1995). The influence of deviant peers on the development of boys' disruptive and delinquent behavior: A temporal analysis. Development and Psychopathology, 7, 715-726. doi:10.1017/S0954579400006805

Kim, H.-S., \& Kim, H. S. (2008). The impact of family violence, family functioning, and parental partner dynamics on Korean juvenile delinquency. Child Psychiatry and Human Development, 39, 439-453. doi: 10.1007/s10578-008-0099-4

Kim, T. E., \& Goto, S. G. (2000). Peer delinquency and parental social support as predictors of Asian American adolescent delinquency. Deviant Behavior, 21, 331-347. doi:10.1080/016396200404122

Kromrey, J. D., \& Foster-Johnson, L. (1998). Mean centering in mod- 
erated multiple regression: Much ado about nothing. Educational and Psychological Measurement, 58, 42-67. doi: $10.1177 / 0013164498058001005$

Lansford, J. E., Criss, M. M., Pettit, G. S., Dodge, K. A., \& Bates, J. E. (2003). Friendship quality, peer group affiliation, and peer antisocial behavior as moderators of the link between negative parenting and adolescent externalizing behavior. Journal of Research on Adolescence, 13, 161-184. doi:10.1111/1532-7795.1302002

Larson, R., \& Richards, M. H. (1991). Daily companionship in late childhood and early adolescence: Changing developmental contexts. Child Development, 62, 284-300. doi:10.2307/1131003

Le, T. N., Monfared, G., \& Stockdale, G. D. (2005).The relationship of school, parent, and peer contextual factors with self-reported delinquency for Chinese, Cambodian, Laotian or Mien, and Vietnamese youth. Crime \& Delinquency, 51, 192-219. doi: $10.1177 / 0011128704273472$

Lipsey, M. W., \& Derzon, J. H. (1998). Predictors of violent or serious delinquency in adolescence and early adulthood: A synthesis of longitudinal research. In R. Loeber, \& D. P. Farrington (Eds.), Serious and violent juvenile offenders: Risk factors and successful interventions (pp. 86-105). Thousand Oaks, CA: Sage.

Liu, R. X., \& Lin, W. (2007.). Delinquency among Chinese adolescents: Modeling sources of frustration and gender differences. Deviant Benhavior, 28, 409-432. doi:10.1080/01639620701233316

Loeber, R. (1982). The stability of antisocial and delinquent child behavior: A review. Child Development, 53, 1431-1446. doi: $10.2307 / 1130070$

Loeber, R., \& Stouthamer-Loeber, M. (1986). Family factors as correlates and predictors of juvenile conduct problems and delinquency. In M. Tonry, \& N. Morris (Eds.), Crime and justice (pp. 29-149). Chicago, IL: University of Chicago Press.

Loeber, R., Farrington, D. P., Stouthmer-Loeber, M., Moffitt, T. E., \& Caspi, A. (1998). The development of male offending: Key findings from the first decade of the Pittsburg Youth Study. Studies on Crime and Crime Prevention, 7, 141-171.

Loeber, R., Stouthamer-Loeber, M., Van Kammen,W., \& Farrington, D. P. (1991). Initiation, escalation, and desistance in juvenile offending and their correlates. Journal of Criminal Law and Criminology, 82, 36-82. doi: $10.2307 / 1143789$

Mason, C. A., Cauce, A. M., Gonzales, N., \& Hiraga, Y. (1994). Adolescent problem behavior: The effect of peers and the moderating role of father absence and the mother-child relationship. American Journal of Community Psychology, 22, 723-743. doi:10.1007/BF02521556

Morris, T. M. (1990). Culturally sensitive family assessment: An evaluation of the Family Assessment Device used with Hawaiian-American and Japanese-American families. Family Process, 29, 105-116. doi:10.1111/j.1545-5300.1990.00105.x

Mrug, S., \& Windle, M. (2009). Moderators of negative peer influence on early adolescent externalizing behaviors. The Journal of Early Adolescence, 29, 518-540. doi:10.1177/0272431608324473

O’Donnell, J., Hawkins, J. D., \& Abbott, R. D. (1995). Predicting serious delinquency and substance use among aggressive boys. Journal of Consulting and Clinical Psychology, 63, 529-537. doi:10.1037/0022-006X.63.4.529

Piquero, N. L., Gover, A. R., MacDonald, J. M., \& Piquero, A. R. (2005). The influence of delinquent peers on delinquency: Does gender matter? Youth \& Society, 36, 251-275. doi: $10.1177 / 0044118$ X04265652

Poole, E. D., \& Regoli, R. M. (1979). Parental support, delinquent fri- ends, and delinquency: A test of interaction effects. Journal of Criminal Law and Criminology, 70, 188-193. doi:10.2307/1142922

Preventing Juvenile Delinquency Law of the People's Republic of China (1999). http://review.jcrb.com/200803/ca689892.htm

Ren, X. (1996). People's Republic of China. In D. J. Shoemaker (Ed.), International handbook on juvenile justice (pp. 57-79). Westport, Conn: Greenwood Press.

Schwartz, S. J., Pantin, H., Prado, G., Sullivan, S., \& Szapocznik, J. (2005). Family functioning, identity, and problem behavior in Hispanic immigrant early adolescents. The Journal of Early Adolescence, 25, 392-420. doi:10.1177/0272431605279843

Shek, D. T. L. (2002). Assessment of family functioning in Chinese adolescents: The Chinese Family Assessment Instrument. In N. N. Singh, T. H. Ollendick, \& A. N. Singh (Eds.), International perspectives on child and adolescent mental health (pp. 297-316). Amsterdam: Elsevier.

Shek, D. T. L. (2005). A longitudinal study of perceived family functioning and adolescent adjustment in Chinese adolescents with economic disadvantage. Journal of Family Issues, 26, 518-543. doi: $10.1177 / 0192513 \times 04272618$

Sullivan, C. J. (2006). Early adolescent delinquency: Assessing the role of childhood problems, family environment, and peer pressure. Youth Violence and Juvenile Justice, 4, 291-313. doi: $10.1177 / 1541204006292656$

Sutherland, E. H., \& Cressey, D. R. (1978). Criminology (10th ed.). Philadelphia: Lippincott.

Thai, N. D. (2003). Vietnamese youth gangs in Honolulu. In C. R. O'Donnell (Ed.), Culture, peers, and delinquency (pp. 47-64). New York: Haworth Press.

Thornberry, T. P., Lizotte, A. J., Krohn, M. D., Farnworth, M., \& Jang, S. J. (1994). Delinquent peers, beliefs, and delinquent behavior: A longitudinal test of interactional theory. Criminology, 32, 47-83. doi:10.1111/j.1745-9125.1994.tb01146.x

Trucco, E. M., Colder, C. R., \& Wieczorek, W. F. (2011). Vulnerability to peer influence: A moderated mediation study of early adolescent alcohol use initiation. Addictive Behaviors, 36, 729-736. doi:10.1016/j.addbeh.2011.02.008

Vitaro, F., Brendgen, M., \& Tremblay, R. E. (2000). Influence of deviant friends on delinquency: Searching for moderator variables. Journal of Abnormal Child Psychology, 28, 313-325. doi:10.1023/A:1005188108461

Warr, M. (2002). Companions in crime: The social aspects of criminal conduct. Cambridge: Cambridge University Press. doi:10.1017/CBO9780511803956

Warr, W. (1993). Parents, peers, and delinquency. Social Forces, 72, 247-264.

Yoshikawa, H. (1994). Prevention as cumulative protection: Effects of early family support and education on chronic delinquency and its risks. Psychological Bulletin, 115, 28-54. doi:10.1037/0033-2909.115.1.28

Zhang, L., \& Messner, S. F. (1996). School attachment and official delinquency status in the People's Republic of China. Sociological Forum, 11, 285-303. doi:10.1007/BF02408368

Zimmerman, M. A., Steinman, K. J., \& Rowe, K. J. (1998). Violence among urban African American adolescents: The protective effects of parental support. In X. B. Arriaga, \& S. Oskamp (Eds.), Addressing community problems: Psychological research and interventions. The Claremont symposium on applied social psychology (pp. 78-103). Thousand Oaks, CA: Sage. 